\title{
Identifikasi Keberadaan Lapisan Akuifer Tertekan (Confined Aquifer) Berdasarkan Data Geolistrik (Studi Kasus : Desa Sambirejo Kecamatan Plupuh Kabupaten Sragen)
}

\author{
Darsono Darsono, Darmanto Darmanto \\ Jurusan fisika FMIPA, Universitas Sebelas Maret \\ onos.dar2014@gmail.com
}

\begin{abstract}
Water occupies a cavity container in the soil called an aquifer. One of the aquifers that is still rarely used is a confined aquifer. This aquifer is located deeper, so the presence needs to be detected first. To detect the presence of confined aquifers using the geoelectric resistivity method. The tool used is the OYO Model 2119C McOHM-EL resistivitimeter, with Schlumberger array with AB / 2 from 1.5 meters up to 350 meters. Data collection was carried out in the District of Plupuh, Sragen Regency with 5 sounding points. Processing data is done with IP2win software.

The results show that the aquifer layer in 5 sounding points is a layer of clay sand, sand and gravel sand layer. A confined aquifer was detected at: TS1 at a depth of 39.9 meters - 110 meters with lithology of gravel sand, TS2 at a depth of 40.25 meters - 66.58 meters and 80.24 -139.7 meters with lithology of sand, TS3 at a depth of 47, 25 meters - 101 meters with lithology of clay sand, TS4 at a depth of 40.72 meters - 103 meters with lithology of clay sand and TS5 at a depth of 31.41 meters - 97 meters with lithology of clay sand.
\end{abstract}

Keywords : Geolelectrics, Schlumberger,confined aquifer

\section{ABSTRAK}

Air menempati suatu wadah rongga di dalam tanah yang disebut dengan akuifer. Salah satu akuifer yang masih jarang digunakan adalah akuifer tertekan. Akuifer ini terletak lebih dalam, sehingga keberadaan perlu dideteksi lebih dahulu. Untuk mendeteksi keberadaan akuifer menggunakan metode geolistrik resistivitas. Alat yang digunakan adalah resistivitimeter OYO Model 2119C McOHM-EL, dengan konfigurasi Schlumberger dengan bentangan AB/2 samapai 350 meter. Pengambilan data dilakukan di Kecamatan Plupuh Kabupaten Sragen sebanyak 5 titik sounding. Pengolahan dilakukan dengan menggunakan software IP2win.

Hasilnya menunjukkan bahwa lapisan akuifer di 5 titik sounding berupa lapisan pasir lempungan, pasir dan lapisan pasir kerikilan. Lapisan akuifer tertekan terdeteksi di: TS1 pada kedalaman 39,9 meter- 110 meter dengan litologi pasir kerikilan, TS2 pada kedalaman 40,25 meter - 66,58 meter dan 80,24 -139,7 meter dengan litologi pasir, TS3 pada kedalaman 47,25 meter - 101 meter dengan litologi pasir lempungan,TS4 pada kedalaman 40,72 meter - 103 meter dengan litologi pasir lempungan dan TS5 pada kedalaman 31,41 meter - 97 meter dengan litologi pasir lempungan.

Kata kunci : Geolistrik, Schlumberger, akuifer tertekan

\section{PENDAHULUAN}

Air merupakan kebutuhan yang sangat vital bagi setiap makhluk hidup. Pertumbuhan dan perkembangan di berbagai bidang akan meningkatkan kebutuhan air, air tanah digunakan untuk kebutuhan air minum, rumah tangga, industri, irigasi, pertambangan, perkotaan dan lainnya, dan telah menjadi komoditas ekonomis bahkan di beberapa tempat telah menjadi komoditas strategis.

Airtanah adalah air yang tersimpan dalam lapisan tanah atau batu di bawah permukaan tanah. Air yang bergerak masuk ke dalam tanah dan tersimpan dalam ruang antara butir-butir 
batuan dan bergabung membentuk lapisan tanah yang disebut akuifer. Lapisan akuifer itu biasanya berpori, permeabel, dan jenuh, dimana lapisan ini disamping dapat mengalirkan air juga dapat menyimpan air, contohnya seperti pasir yang tidak terkonsolidasi, kerikil, batuan sedimen, terutama batu gamping dan dolomit, batupasir konglomerat dan batuan vulkanik berpori atau retak ${ }^{[1]}$. lapisan impermeable merupakan lapisan yang sulit mengalirkan air yang disebut sebagai akuiclud atau akuitar contohnya lempung. Akuifer dibedakan menjadi 3 yaitu akuifer bebas (unconfined aquifer), Akuifer semi tertekan (leaky aquifer) dan akuifer tertekan (confined aquifer) ${ }^{[2]}$. Ilustrasi skema system akuifer dalam tanah seperti Gambar 1.

Permasalahan musim kemarau ketersediaan air semakin terbatas, debit air menjadi sangat kecil sehingga jumlah air sangat terbatas dan tidak dapat mencukupi kebutuhan bagi makhluk hidup, bahkan kalau terjadi kemarau panjang dapat mengalami kekeringan. Dampak kekeringan dirasakan disebagian besar di wilayah Kabupaten Sragen terutama kecamatan Plupuh. Pada umumnya masyarakat banyak yang menggunakan airtanah yang berasal dari akuifer bebas/semi tertekan. Lapisan akuifer ini sangat bergantung dengan musim, sedangkan untuk sumber air yang berasal dari akuifer tertekan masih jarang digunakan masyarakat dan keberadaannya berada lebih dalam di bawah permukaan. Keberadaan akuifer airtanah di suatu tempat berbeda-beda baik kedalamannya maupun jenis litologinya. Untuk melakukan pengeboran tidak boleh sembarangan, apabila melakukan pengeboran langsung tanpa survey keberadaan akuifer, bisa jadi pengeboran nihil/kosong tanpa mendapatkan sumber air tanah. Untuk mengidentifikasi keberadaan lapisan akuifer dalam dapat dilakukan survey menggunakan salah satu metode geofisika yaitu metode resistivitas. Penggunaan metode geolistrik resistivitas pernah dilakukan peneliti sebelumnya seperti penentuan parameter akuifer di Khanewal District Paskistan ${ }^{[3]}$, penentuan potensi airtanah ${ }^{[4]}$, penentuan zone akuifer airfresh ${ }^{[5]}$, identifikasi akuifer dalam dan dangkal di kecamatan Masaran, dan Sambirejo Sragen ${ }^{[6]}$.

Berdasarkan peta geologi, kecamatan plupuh Saregen termasuk dalam endapan Gunung Api Muda, yang berasal dari kegiatan Gunung Lawu. Endapan Gunung api muda ini terdiri dari lapisan lempung, lempung pasiran, pasir lempungan, pasir, pasir kerikilan dan breksi volkanik, kedudukan dengan formasi Notopuro tidak selaras ${ }^{[7]}$.

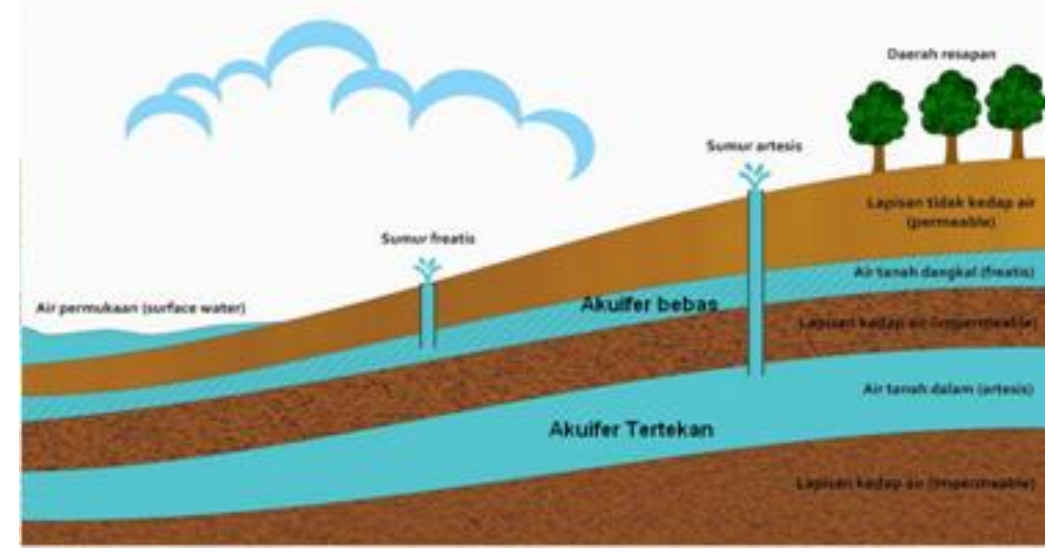

Gambar 1. Skema Lapisan Airtanah ${ }^{[2]}$ 


\section{METODE}

Penelitian ini dilakukan di Desa Sambirejo Kecamatan Plupuh Kabupaten Sragen (Gambar 2). Pengukuran dilakukan dengan menggunakan Resistivitymeter OYO Model 2119C McOHM-EL. Pengukuran geolistrik dilakukan sebanyak 5 (lima) titik sounding, Lokasi pengukuran seperti Tabel 1.

Tabel 1. Lokasi Pengukuran Geolistrik

\begin{tabular}{|c|c|c|c|c|c|}
\hline \multirow[t]{2}{*}{ No } & \multirow{2}{*}{$\begin{array}{l}\text { Titik } \\
\text { Sounding }\end{array}$} & \multirow[t]{2}{*}{ Lokasi } & \multicolumn{3}{|c|}{ Koordinat } \\
\hline & & & $\mathrm{Y}(\mathrm{S})$ & $X(E)$ & $\mathrm{Z}(\mathrm{m})$ \\
\hline 1. & TS 1 & $\begin{array}{l}\text { Dk.Sambirejo, } \\
\text { Plupuh }\end{array}$ & $07^{\circ} 25^{\prime} 20.02^{\prime \prime}$ & $110^{\circ} 53^{\prime} 19.5^{\prime \prime}$ & 108 \\
\hline 2. & TS 2 & $\begin{array}{l}\text { Dk.Sambirejo, } \\
\text { Pulupuh }\end{array}$ & $07^{\circ} 25^{\prime} 24,9^{\prime}$, & $110^{\circ} 53^{\prime} 14.7^{\prime}$ & 97 \\
\hline 3. & TS 3 & $\begin{array}{l}\text { Dk. Karang Ds. } \\
\text { Sambirejo, Kec Plupuh }\end{array}$ & $07^{\circ} 25^{\prime} 16.7^{\prime \prime}$ & $110^{\circ} 52^{\prime} 54.7^{\prime \prime}$ & 117 \\
\hline 4. & TS 4 & $\begin{array}{l}\text { Dk. Sambiroto, Ds. } \\
\text { Ngrombo Sambirejo } \\
\text { Kec. Plupuh }\end{array}$ & $07^{\circ} 25^{\prime} 02.3$ ', & $110^{\circ} 52^{\prime} 15.5^{\prime}$ & 138 \\
\hline 5. & TS 5 & $\begin{array}{l}\text { Dk. Ceperan } \\
\text { Sambirejo }\end{array}$ & $07^{\circ} 25^{\prime} 16.6^{\prime \prime}$ & $110^{\circ} 52^{\prime} 41.7^{\prime}$ & 133 \\
\hline
\end{tabular}

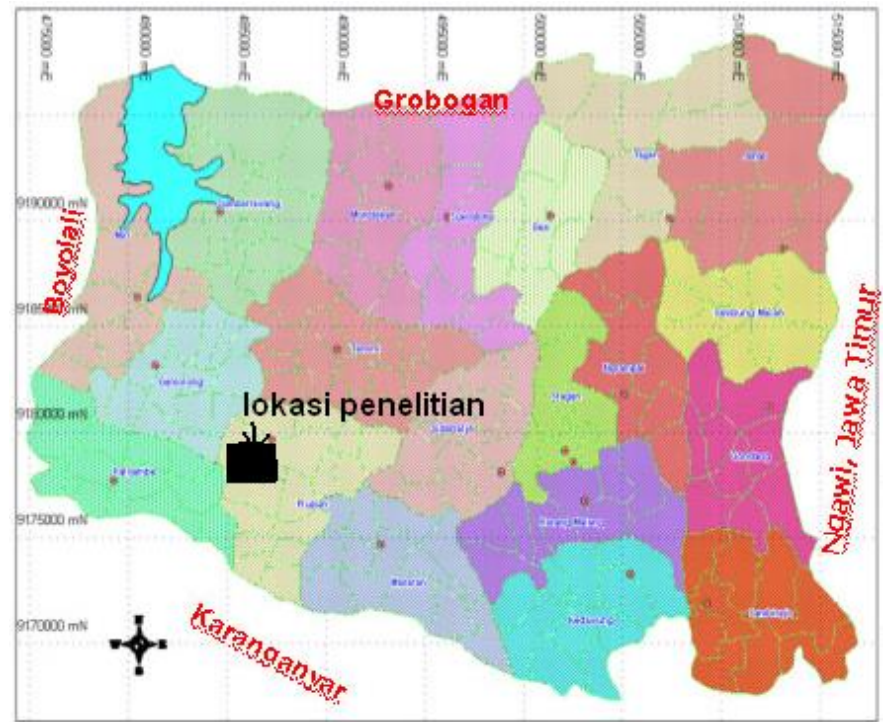

Gambar 2. Peta kabupaten Sragen lokasi penelitian

Metode yang digunakan adalah metode geolistrik resistivitas, dimana metode ini mempelajari sifat resistivitas listrik dari lapisan batuan di dalam bumi. Prinsip kerjanya adalah dengan menginjeksikan arus ke dalam bumi dengan melalui dua elektroda arus selanjutnya potensial yang timbul ditangkap dengan menggunakan 2 elektroda potensial. Dari data arus dan beda potensial untuk setiap jarak elektroda tertentu, dapat ditentukan variasi harga hambatan jenis masing-masing lapisan di bawah titik ukur (titik sounding) ${ }^{[8]}$. Untuk jelasnya penjabaran rumus nilai resistivitas semu ${ }^{[9]}$.

$$
\rho_{a}=K \frac{\Delta \vec{V}}{\vec{I}}
$$


$\rho_{a}=$ hambatan jenis semu, $K=$ faktor geometeri, $\Delta \vec{V}=$ beda potensial, $I=$ arus yang diinjeksikan. Pada penelitian konfigurasi yang dipakai adalah konfigurasi Schlumberger, susunan elektrodanya seperti Gambar 3.

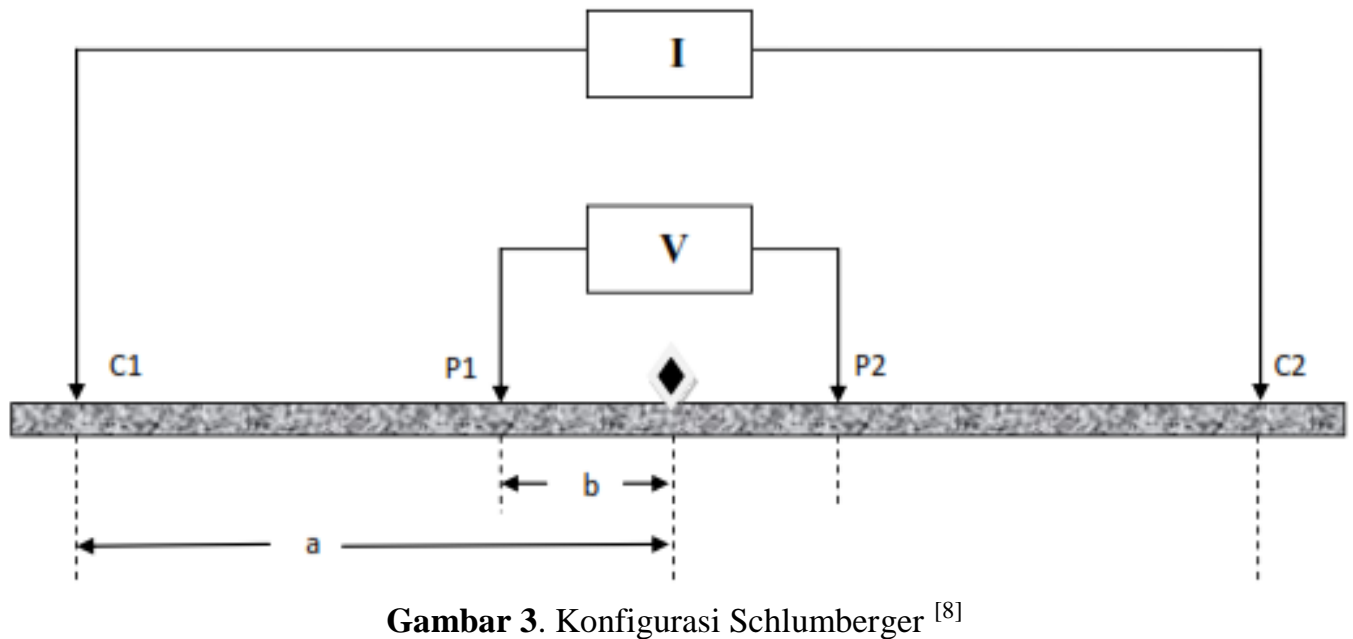

Keterangan C1,C2 : elektroda Arus, P1,P2 : elektroda Potensial, b : jarak elektroda potensial ke titik ukur, a: jarak elektroda arus ke titik ukur.

Pengolahan data dilakukan menggunakan software IP2win dengan inputan data AB/2 dan nilai resistivitas semu. Hasil pengolahan berupa kedalaman, ketebalan lapisan dan nilai resistivitas sesungguhnya. Selanjutnya dilakukan interpretasi dengan membandingkan hasil dengan nilai resistivitas batuan dan peta geologi daerah penelitian. Nilai resitivitas batuan seperti Tabel 2.

Tabel 2. Nilai resistivitas batuan ${ }^{[9]}$

\begin{tabular}{ll}
\hline \multicolumn{1}{c}{ Material } & Resisitivitas (囚m) \\
\hline Udara (Air) & $\sim$ \\
Pirit (Pyrite) & $0,01-100$ \\
Kwarsa (Quartz) & $500-800000$ \\
Kalsit (Calcite) & $1 \times 10^{12}-1 \times 10^{13}$ \\
Garam Batu (Rock Salt) & $30-1 \times 10^{13}$ \\
Granit (Granite) & $200-10000$ \\
Andesite (Andesite) & $1,7 \times 10^{2}-45 \times 10^{4}$ \\
Basal (Basalt) & $200-100000$ \\
Gamping (Limestone) & $500-10000$ \\
Batu pasir (Sandstone) & $200-8000$ \\
Batu tulis (Shales) & $20-2000$ \\
Pasir (sand) & $1-1000$ \\
Lempung (Clay) & $1-100$ \\
Air tanah (Ground water) & $0,5-300$ \\
Air asin (Sea water) & 0,2 \\
Magnetit (Magnetite) & $0,01-1000$ \\
Kerikil kering (Dry gravel) & $600-10000$ \\
Aluvium (Alluvium) & $10-800$ \\
Kerikil (Gravel) & $100-600$ \\
\hline
\end{tabular}




\section{HASIL DAN PEMBAHASAN}

Pengolahan data geolistrik dilakukan dengan menggunakan software IP2Win. Hasil pendugaan geolistrik berdasarkan hasil pengolahan data geolistrik di setiap titik pengukuran dan dengan mempertimbangkan kondisi geologi dan hidrogeologi serta memperhatikan referensi kisaran nilai tahanan jenis batuan, maka selanjutnya dikelompokkan jenis batuan berdasarkan nilai tahanan jenis sebenarnya. Tabel 3,4,5,6,7 merupakan hasil dari pengolahan data dan sudah diinterpretasi dalam litologi dan jenis lapisan setiap lapisan.

Tabel 3. Jenis litologi pada titik pengukuran TS1(Ds. Sambirejo, Kec. Plupuh)

\begin{tabular}{cccccc}
\hline No. & $\begin{array}{c}\text { Kedalaman } \\
(\mathrm{m})\end{array}$ & $\begin{array}{c}\text { Ketebalan } \\
(\mathrm{m})\end{array}$ & $\begin{array}{c}\text { Tahanan } \\
\text { Jenis } \\
(\Omega \mathrm{m})\end{array}$ & Litologi & Keterangan \\
\hline 1. & $0-1,07$ & 1,07 & 7,47 & Top Soil & Lapisan penutup \\
akuiklud \\
2. & $1,07-1,69$ & 0,626 & 2,32 & Lempung & akuitar \\
3. & $1,69-7,75$ & 6,06 & 7,22 & Lempung pasiran & Akuifer tak tertekan \\
4. & $7,75-19,2$ & 11,5 & 31,6 & Pasir & akuiklud \\
5. & $19,2-31,8$ & 12,6 & 2,15 & Lempung & Akuitar \\
6. & $31,8-39,9$ & 8,07 & 7,64 & Lempung pasiran & Akuifer tertekan \\
7. & $39,9-110$ & 70,2 & 69,3 & Pasir kerikilan & akuiklud \\
8. & $110-161$ & 50,8 & 2,13 & Lempung & akuiklud \\
9. & $>161$ & & 1,14 & Lempung & . \\
\hline
\end{tabular}

Tabel 4. Jenis litologi pada titik pengukuran TS2 (Ds. Sambirejo Kec. Plupuh)

\begin{tabular}{cccccc}
\hline No. & $\begin{array}{c}\text { Kedalaman } \\
(\mathrm{m})\end{array}$ & $\begin{array}{c}\text { Ketebalan } \\
(\mathrm{m})\end{array}$ & $\begin{array}{c}\text { Tahanan } \\
\text { Jenis } \\
(\Omega \mathrm{m})\end{array}$ & Litologi & Keterangan \\
\hline 1. & $0-2,566$ & 2,566 & 6,706 & Soil & Lapisan penutup \\
2. & $2,566-3,579$ & 1,013 & 13,69 & Lempung pasiran & Akuitar \\
3. & $3,579-5,56$ & 2,072 & 29,25 & Pasir & Akuifer tak tertekan \\
4. & $5,56-32,02$ & 26,37 & 13,3 & Lempung Pasiran & akuitar \\
5. & $32,02-40,25$ & 8,229 & 4,148 & Lempung & akuiklud \\
6. & $40,25-66,58$ & 25,34 & 36,01 & Pasir & Akuifer tertekan \\
7. & $66,58-80,24$ & 14,66 & 2,972 & Lempung & akuiklud \\
8. & $80,24-139,7$ & 59,42 & 37,45 & Pasir & Akuifer tertekan \\
9. & $>139,7$ & & 1,699 & Lempung & akuiklud \\
\hline
\end{tabular}


Tabel 5. Jenis litologi pada titik pengukuran TS3(Dk.Karang Ds. Sambirejo, kec. Plupuh)

\begin{tabular}{cccccc}
\hline No. & $\begin{array}{c}\text { Kedalaman } \\
(\mathrm{m})\end{array}$ & $\begin{array}{c}\text { Ketebalan } \\
(\mathrm{m})\end{array}$ & $\begin{array}{c}\text { Tahanan } \\
\text { Jenis } \\
(\Omega \mathrm{m})\end{array}$ & Litologi & Keterangan \\
\hline 1. & $0-1$ & 1 & 6.396 & Soil & Lapisan penutuo \\
2. & $1-7.450$ & 6.450 & 23.5 & Pasir lempungan & Akuifer tak tertekan \\
3. & $7.450-15.62$ & 8.162 & 31.16 & Pasir & Akuifer tak tertekan \\
4. & $15.62-24.25$ & 8.627 & 13.1 & Lempung pasiran & akuitar \\
5. & $24.25-47.25$ & 23 & 8.04 & Lempung pasiran & akuitar \\
6. & $47.25-101.6$ & 54.38 & 22.59 & Pasir lempungan & Akuifer tertekan \\
7. & $101.6-186$ & 84.35 & 1.122 & Lempung & akuiklud \\
8. & $>186$ & & 21.55 & Pasir lempungan & Akuifer tertekan \\
\hline
\end{tabular}

Tabel 6. Jenis litologi pada titik pengukuran TS 4 (Dk.Sambiroto, Ds. Ngrombo, Plupuh)

\begin{tabular}{cccccc}
\hline No. & $\begin{array}{c}\text { Kedalaman } \\
(\mathrm{m})\end{array}$ & $\begin{array}{c}\text { Ketebalan } \\
(\mathrm{m})\end{array}$ & $\begin{array}{c}\text { Tahanan } \\
\text { Jenis } \\
(\Omega \mathrm{m})\end{array}$ & Litologi & Keterangan \\
\hline 1. & $0-4,107$ & 4,107 & 21,29 & Soil & Lapisan penutup \\
2. & $4,107-5,457$ & 1,27 & 11,78 & Lempung pasiran & akuitar \\
3. & $5,457-8,507$ & 3,05 & 51,85 & Pasir & Akuifer tak tertekan \\
4. & $8,507-13,18$ & 4,67 & 4,272 & Lempung & Akuiklud \\
5. & $13,18-15,4$ & 2,22 & 14,31 & Lempung pasiran & akuitar \\
6. & $15,4-30,03$ & 14,63 & 35,71 & Pasir & Akuifer tak tertekan \\
7. & $30,03-46,72$ & 16,69 & 1,91 & Lempung & Akuiklud \\
8. & $46,72-103,4$ & 56,68 & 21,47 & Pasir lempungan & Akuifer tertekan \\
9. & $103,4-116,4$ & 13,04 & 1,054 & Lempung & akuiklud \\
10. & $>116,4$ & & 0,134 & Lempung & akluiklud \\
\hline
\end{tabular}

Tabel 7. Jenis litologi pada titik pengukuran TS5 (Dk. Ceperan, Ds. Sambirejo, Plupuh)

\begin{tabular}{cccccc}
\hline No. & $\begin{array}{c}\text { Kedalaman } \\
(\mathrm{m})\end{array}$ & $\begin{array}{c}\text { Ketebalan } \\
(\mathrm{m})\end{array}$ & $\begin{array}{c}\text { Tahanan } \\
\text { Jenis }(\Omega \mathrm{m})\end{array}$ & Litologi & Keterangan \\
\hline 1. & $0-1,755$ & 1,755 & 10,83 & Soil & Lapisan penutup \\
2. & $1,755-4,07$ & 2,315 & 54,58 & Pasir & Akuifer tek tertekan \\
3. & $4,07-12,99$ & 8,916 & 22,11 & Pasir lempungan & Akuifer tak tertekan \\
4. & $12,99-17,56$ & 4,577 & 71,82 & Pasir kerikilan & Akuifer tak tertekan \\
5. & $17,56-21,29$ & 3,728 & 12,13 & Lempung pasiran & Akuitar \\
6. & $21,29-31,41$ & 10,12 & 7,88 & Lempung pasiran & Akuitar \\
7. & $31,41-97,01$ & 65,6 & 19.79 & Pasir lempungan & Akuifer tertekan \\
8. & $97,01-108,1$ & 11,13 & 1,174 & Lempung & Akuiklud \\
9. & $108,1-118,3$ & 10,17 & 0,84 & Lempung & Akuiklud \\
10. & $>118,3$ & & 9,911 & Lempung pasiran & Akuitar \\
\hline
\end{tabular}

Dari kelima titik sounding terdeteksi lapisan akuifer dengan jenis litologi pasir lempungan, pasir, pasir kerikilan, sedangkan lapisan bukan akuifer terdeteksi berupa lempung dan lempung pasiran. Dari kelima tabel di atas (Tabel 3,4,5,6,7) dapat diidentifikasikan jenis akuifer beserta kedalaman, ketebalan dan jenis litologinya, seperti Tabel 8. Besar kecilnya 
debit air bergantung dari ketebalan lapisan dan jenis litologinya. Akuifer tak tertekan biasa digunakan untuk penduduk untuk konsumsi air yang sedikit, jika akuifer tak tertekan sudah tidak mencukupi kebutuhan, maka perlu dilakukan eksplorasi akuifer alternatif yaitu akuifer tertekan. Akuifer ini terletak di bawah akuifer tak tertekan dan masih jarang digunakan. Tabel 8, terlihat bahwa pada TS1 terdeteksi akuifer tertekan yang mempunyai litologi pasir kerikilan dan mempunyai ketebalan 70,2 m. TS1 diperkirakan mempunyai debit paling besar dibandingkan titik sounding yang lain. Yang kedua TS2 terdeteksi akuifer tertekan dengan litologi pasir dengan ketebalan 84,7 m. Diperkirakan lokasi ini juga mempunyai debit air yang besar dibandingkan titik sounding yang lain selain TS1. Sedangkan untuk TS3,TS4 dan TS5 terdeteksi dengan litologi pasir lempungan dengan ketebalan lapisan bervariasi. Pada ketiga titik ini mempunyai debit yang lebih kecil dibandingkan TS1 dan TS2.

Tabel 8. Kedalaman lapisan akuifer tertekan

\begin{tabular}{|c|c|c|c|c|}
\hline Lokasi & Kedalaman & ketebalan & Litologi & Jenis akuifer \\
\hline \multirow[t]{2}{*}{ TS1 } & $7,75-19,2$ & 11,5 & Pasir & Akuifer tak tertekan \\
\hline & $39,9-110$ & 70,2 & Pasir kerikilan & Akuifer Tertekan \\
\hline \multirow[t]{3}{*}{$\mathrm{TS} 2$} & $3,57-5,56$ & 2,07 & Pasir & Akuifer tak tertekan \\
\hline & $40,25-66,58$ & 84,76 & Pasir & Akuifer Tertekan \\
\hline & $80,24-139,7$ & & & \\
\hline \multirow[t]{2}{*}{ TS3 } & $1-15,62$ & 14,62 & Pasir lempungan dan pasir & Akuifer tak tertekan \\
\hline & $\begin{array}{c}47,25-101,6 \\
>186\end{array}$ & 54,35 & Pasir lempungan & Akuifer Tertekan \\
\hline \multirow[t]{2}{*}{ TS4 } & $\begin{array}{c}5,4-8,5 \\
15,4-30,03\end{array}$ & 17,68 & Pasir & Akuifer tak tertekan \\
\hline & $46,72-103,4$ & 56,68 & Pasir lempungan & Akuifer tertekan \\
\hline \multirow[t]{2}{*}{ TS5 } & $1,75-17,56$ & 15,8 & $\begin{array}{l}\text { Pasir lempungan, pasir, } \\
\text { pasir kerikilan }\end{array}$ & Akuifer tak tertekan \\
\hline & $31,41-97$ & 65,6 & Pasir lempungan & Akuifer tertekan \\
\hline
\end{tabular}

\section{KESIMPULAN}

Lapisan akuifer tertekan terdeteksi berupa lapisan pasir lempungan, pasir dan pasir kerikilan. Lapisan akuifer tertekan terdeteksi pada kedalaman 39,9 meter sampai 139,7 meter. Pada TS1 dan TS2 merupakan lapisan akuifer tertekan yang potensial mempunyai debit yang lebih besar.

\section{DAFTAR PUSTAKA}

1 R. Allan Freeze, John A. Cherry. 1979. Groundwater,.Prentice-Hall. Universitas Michigan

2 Kodoatie, J.K, 2013, Tata Ruang Air Tanah. penerbit Andy, Yogyakarta

3 Gulraiz Akhter and M. Hasan. 2016. Determination of aquifer parameters using geoelectrical sounding and pumping test data in Khanewal District, Pakistan. Open Geosci. 2016; 8:630-638

4 Oseji J.O., Asokhia M.B., Okolie E.C.2006. Determination of groundwater potential in obiaruku and environs using surface geoelectric sounding. Environmentalist, , 26, 301308 
5 UkoEtim D. 2015. Determination of Aquiferous Zones in the Freshwater South-East Niger Delta, Using Vertical Electrical Sounding (VES) Method. Journal of Geography, Environment and Earth Science International, 2(2), 54-64

6 Darsono, 2016. Identifikasi Akuifer Dangkal dan Akuifer Dalam dengan Metode Geolistrik (studi kasus : kecamatan Masaran, Sragen), Indonesian Journal of Applied Physics. 40-49

7 Suharyadi, 2004, Laporan Akhir Penelitian Geolistrik Di Kecamatan Gemolong Kab. Sragen., Laboratorium Geologi Tata Lingkungan Jurusan Teknik Geologi Fakultas Teknik Universitas Gadjah Mada, Yogyakarta

8 Lilik Hendrajaya dan Idam Arif., 1990, Geolistrik Tahanan Jenis. Laboratorium Fisika Bumi Jurusan Fisika FMIPA., ITB

9 Telford W.M., Geldart L.P., Sheriff R.E., Keys D.A., 1998, Applied Geophysics, Cambridge University Press 